\title{
A importância do Distrito Federal na composição do mercado de emprego celetista da Região Centro-Oeste do Brasil
}

\author{
Carlos Antônio de Rezende* \\ Alcido Elenor Wander \\ Paulo Cesar Bontempo****
}

\begin{abstract}
Resumo
Este trabalho visa demonstrar a importância socioeconômica do Distrito Federal para a Região Centro-Oeste, considerando-se o contexto histórico e geográfico da região, suas características, sua evolução demográfica e seu mercado de trabalho. A abordagem metodológica foi baseada em dados secundários, com a utilização do modelo shift-share para a análise do componente estrutural e regional. Os resultados encontrados demonstram que o componente regional teve uma contribuição positiva sobre o emprego formal em todos os setores no estado do Mato Grosso. Já o componente estrutural foi positivo no Distrito Federal e em Goiás, considerando os setores secundário e terciário. Nesses estados, o componente estrutural foi negativo no setor primário. Em Mato Grosso do Sul, o componente estrutural também foi positivo nos setores secundário e terciário, mas foi negativo no setor primário. Apenas no Mato Grosso, o setor primário teve um desempenho favorável no componente regional.
\end{abstract}

Palavras-chave: Distrito Federal. Centro-Oeste. Socioeconômico. Composição de Empregos. Shift-share.

* Mestre em Desenvolvimento Regional. Analista de Planejamento e Orçamento do Ministério do Planejamento, Orçamento e Gestão, atualmente em exercício no Ministério da Justiça. Professor do Centro de Ensino Unificado de Brasília (UniCEUB). E-mail: carezbsb@yahoo.com.br

** Doutor em Ciências Agrárias (Economia Rural). Pesquisador da Empresa Brasileira de Pesquisa Agropecuária (Embrapa) na área de Socioeconomia. Professor do Programa de Pós-Graduação (Mestrado) em Desenvolvimento Regional das Faculdades Alves Faria (Alfa), Goiânia-GO. Autor de correspondência. E-mail: alcido.wander@embrapa.br

*** Doutor em Administração. Professor do Programa de Pós-Graduação (Mestrado) em Desenvolvimento Regional das Faculdades Alves Faria (Alfa), em Goiânia-GO. E-mail: pcbontempo@gmail.com

http://dx.doi.org/10.5335/rtee.v21i44.5361

Submissão: 20/08/2013. Aceite: 17/12/2014. 


\section{Introdução}

O Distrito Federal (DF) é uma das 27 unidades federativas do Brasil e é constituído por 30 regiões administrativas. Localizado na Região Centro-Oeste do país, circundado pelo estado de Goiás, do qual foi extraído, foi o principal responsável pela expansão da interiorização rumo à região.

Segundo dados do Censo 2009 do Instituto Brasileiro de Geografia e Estatísticas (IBGE), o Distrito Federal abriga uma população de 2.606.885 habitantes, que ocupam uma área de $5.822,1 \mathrm{~km}^{2}$, o que representa densidade populacional de aproximadamente 443 habitantes $/ \mathrm{km}^{2}$. Seu relevo é caracterizado pela predominância de áreas planas e elevadas, colinas arredondadas e chapadas intercaladas por escarpas. Sua altitude média é de 1.100 metros e seu ponto mais elevado fica a 1.349 metros acima do nível do mar.

Apresenta solo pobre em nutrientes, mas rico em ferro e alumínio. Devido à sua formação ser antiga, o solo tem pouca capacidade de absorver água, embora exista uma grande reserva do líquido no subsolo.

O clima é tropical de altitude, com verão úmido e chuvoso e inverno seco, com uma temperatura média anual por volta de $20^{\circ} \mathrm{C}$. A umidade relativa do ar varia de $15 \%$, na época de seca, a $80 \%$.

A vegetação típica do Distrito Federal é o cerrado, que tem como características árvores com troncos retorcidos, folhas e cascas grossas. Esse bioma está sendo bastante degradado e estima-se que quase $70 \%$ já tenha sido devastado no Distrito Federal.

Além de Brasília, a composição atual do Distrito Federal comporta mais 29 regiões administrativas: Gama, Taguatinga, Brazlândia, Sobradinho, Planaltina, Paranoá, Núcleo Bandeirante, Ceilândia, Guará, Cruzeiro, Samambaia, Santa Maria, São Sebastião, Recanto das Emas, Lago Sul, Riacho Fundo, Lago Norte, Candangolândia, Águas Claras, Riacho Fundo II, Sudoeste/Octogonal, Varjão, Park Way, Estrutural, Sobradinho II, Jardim Botânico, Itapoá, SAI e Vicente Pires.

Neste artigo, objetiva-se demonstrar a importância socioeconômica do Distrito Federal para a Região Centro-Oeste, considerando-se seu contexto histórico e geográfico, suas características e a evolução demográfica e do mercado de trabalho da região.

A abordagem metodológica utilizou dados secundários extraídos de publicações históricas e econômicas, de dados estatísticos por meio do modelo shift-share para analisar as mudanças ocorridas.

O trabalho reverte-se de importância a partir da constatação de que a transferência da capital federal para o interior alterou as composições econômica, social e demográfica do país, transformando uma região até então tímida em uma das mais 
importantes na produção de grãos do Brasil e que busca agora um diferencial de agregação de valor econômico.

\section{Aspectos históricos e socioeconômicos}

Desde o século XVIII os intelectuais clamavam por uma capital do país em seu interior. Esse debate foi um dos mais alongados da história do Brasil. Contudo, somente em 1892, o presidente Floriano Peixoto designa Luiz Crulls para uma missão que demarcaria a região em que ficaria a futura capital. Essa missão, conhecida como Missão Crulls, durou até 1894. No ano seguinte ao início dessa missão, foi publicado o primeiro mapa que incluía a demarcação de um quadrilátero com a designação de Futuro Distrito Federal.

Um fator preponderante para o início da interiorização do país rumo ao Centro-Oeste foi o lançamento, pelo governo federal, da Marcha para o Oeste. Conforme Timm (2010, p. 36), a "Marcha para o Oeste" foi lançada pelo presidente Getúlio Vargas em Goiânia, no ano de 1940.

Bertran afirma que a Marcha para o Oeste, entre 1943 e 1953, foi:

Uma ação regional mais complexa, somando à criação de Goiânia as Colônias de Goiás (Ceres e Rialma) e de Mato Grosso e instituindo, em 1943, a Fundação Brasil Central, a qual absorvia algumas das funções da Comissão Rondon nos trabalhos de penetração do território e alocação do povoamento [...] (1988, p. 98).

Bertran (1988, p. 99) relata, entretanto, que durante toda a década de 1940 , Goiânia continuava praticamente inerte, em virtude de uma série de acontecimentos econômicos e políticos que a isolaram economicamente do resto do país.

Timm (2010, p. 39) relata que em 1950 foi aprovada pelo Senado Federal a lei que determinava a localização da futura capital. O compromisso de transferir a nova capital federal para o interior foi firmado pelo então candidato à Presidência da República Juscelino Kubitscheck de Oliveira (JK) em comício, em praça pública, na cidade de Jataí, em 1955, quando perguntado sobre o assunto por um cidadão de nome Antônio Soares Neto, o Toniquinho.

Eleito presidente do Brasil em outubro de 1955, JK, já em setembro do ano seguinte, lançou o concurso que definiria o projeto de construção da nova capital. O resultado foi apresentado em 1957 e teve como vencedor o projeto apresentado por Lúcio Costa.

Durante o processo de construção da nova capital, várias obras foram inauguradas, com destaque para a estrada asfaltada que liga Brasília a Anápolis, em 
1958. Essa estrada é hoje a BR 040 e está totalmente duplicada no trecho que liga Brasília a Goiânia.

Dessa forma, Bertran (1988, p. 99) destaca que, nas décadas de 1950 e 1960, a construção de Brasília impactou positivamente as economias de Goiânia e de Anápolis, duas tímidas cidades agrário-mercantis. Os ganhos advindos do surto agrário goiano migraram para o novo mercado aberto com as obras e a implantação da nova capital federal, que se mostrava uma grande oportunidade de investimento. Em 21 de abril de 1960, foi inaugurada Brasília, a nova capital do Brasil, e em 1961 foi aprovada a Emenda Constitucional nํㅜ 3, que fixou a nomeação do governador do Distrito Federal pelo presidente da República, ouvido o Senado Federal.

Segundo Timm (2010), após a inauguração, Brasília e o país passaram por turbulências, que culminaram com a aprovação, pelo Congresso Nacional, do Ato Institucional $\mathrm{n}^{\circ}$ 1, que nomeou o marechal Humberto de Alencar Castelo Branco presidente da República, em substituição ao presidente João Goulart. Esse foi o início de um regime de exceção que durou até 1985, quando tomou posse o novo presidente da República, José Sarney, um civil, porém, sem ser eleito como tal, já que ele era candidato ao cargo de vice-presidente na chapa encabeçada por Tancredo Neves, que não tomou posse por motivo de saúde. Essa foi a última eleição para presidente da República do Brasil via colégio eleitoral.

Em 1990, tomou posse o presidente Fernando Collor de Mello, eleito pelo voto direto. Foi um governo que não chegou ao final, pois, em virtude de denúncias de corrupção, o Congresso Nacional cassou o seu mandato, e assumiu o seu vice-presidente, Itamar Franco, em 1993. Itamar Franco, juntamente com seu ministro da Fazenda, Fernando Henrique Cardoso, lançou o Plano Real e conseguiu controlar a inflação. Esse fato foi primordial para que o ministro Fernando Henrique fosse eleito, mais tarde, presidente da República.

Timm (2010) relata que em 1990 foram realizadas eleições diretas pela primeira vez para o governo do Distrito Federal e para a sua Câmara Distrital, e que, em 1993, a Câmara Distrital aprovou a Lei Orgânica do Distrito Federal. A partir de 1994, já com mais de 1 milhão de habitantes, o Distrito Federal passou a conviver com os problemas inerentes às grandes cidades, principalmente quanto ao trânsito e à insegurança.

Brasília sempre se caracterizou por um envolvimento político bem acentuado de sua população. Vários movimentos populares tiveram início na Esplanada dos Ministérios: manifestações pelas eleições diretas, pela cassação do presidente Fernando Collor, pela cassação do governador Roberto Arruda, também envolvido em denúncias de corrupção, são alguns exemplos. 
O Ministério da Integração Nacional (2014, p. 25-36) confirma a importância socioeconômica do Distrito Federal para a Região Centro-Oeste, em sua análise sobre a região em relação ao resto do país, mostrando que ao mesmo tempo em que o nível de pobreza caiu, o produto interno bruto (PIB), o Índice de Desenvolvimento Humano (IDH), o nível de escolaridade e o número de pessoas beneficiadas com água encanada e esgotamento sanitário melhoraram acima da média nacional, principalmente, por conta da presença da capital federal na região.

De acordo com Pagnussat (2010, p. 23), o IDH do DF é de 0,849, um índice encontrado em países desenvolvidos, acima da média nacional. Segundo o autor, o alto IDH detectado deve-se às boas condições de saúde, à elevada renda per capita e à elevada escolaridade. $\mathrm{O}$ autor destaca ainda que $50 \%$ dos servidores públicos têm nível de ensino superior e 30\%, nível médio. Levando-se em consideração que o serviço público é responsável por quase 50\% do PIB local, detecta-se a importância da educação na economia local.

Pagnussat (2010, p. 25) relata que a participação percentual do Centro-Oeste no PIB nacional mais do que triplicou entre 1960, ano da inauguração de Brasília, e 2010. Ainda, segundo o autor, Brasília detém um PIB que supera $\mathrm{R} \$ 100$ bilhões, e está entre as oito principais economias do país. Ressalte-se a importância do setor de serviços, que é responsável por $92 \%$ desse PIB, ficando a indústria com $7 \%$ e a agricultura com $1 \%$ desse total.

Segundo Miragaya (2010, p. 4), entre 1970 e 2007, o PIB do Centro-Oeste do país saltou de $3,8 \%$ em 1970, para 9,85\% em 2007, atribuindo-se grande parte desse salto à existência de Brasília, que participou com $\mathrm{R} \$ 262,1$ bilhões.

A Tabela 1 apresenta de forma resumida a representatividade do DF para o PIB da região. Segundo os dados apresentados, o DF detinha, em 2007, mais de $42 \%$ do PIB da região. É possível observar a importância do serviço público no valor adicionado e a importância do setor da construção civil, que, em relação à Região Centro-Oeste, apresenta mais de $32 \%$ do total.

Tabela 1 - Participação percentual dos setores da economia no Distrito Federal em 2007

\begin{tabular}{l|c|c|c}
\hline \multicolumn{1}{c|}{ Discriminação } & Valor adicionado do DF & DF/ Centro-Oeste & DF/ Brasil \\
\hline Agropecuária & 0,29 & 1,25 & 0,21 \\
Indústria & 6,55 & 18,6 & 0,92 \\
Construção Civil & 3,60 & 32,04 & 2,90 \\
Serviços & 93,16 & 53,46 & 5,49 \\
Administração pública & 53,76 & 72,34 & 13,65 \\
Participação \% PIB & - & 42,36 & 3,76 \\
\hline
\end{tabular}

Fonte: IBGE (2009); Codeplan (2010). 
No que se refere ao mercado de trabalho, em 2010, segundo dados da Pesquisa de Emprego e Desemprego (PED) do Departamento Intersindical de Estatística e Estudos Socioeconômicos (DIEESE, 2010), 64,8\% do pessoal empregado no Distrito Federal estavam alocados no setor de serviços, conforme ilustra a Tabela 2. Outros $16,4 \%$ estavam alocados no comércio, em virtude do desenvolvimento desse setor, principalmente, em face ao bom poder aquisitivo da população, o que caracteriza um mercado consumidor muito promissor.

A construção civil absorvia 5,7\% da mão de obra empregada, em virtude da expansão imobiliária, via obras públicas e construção de unidades habitacionais, visando atender a uma demanda reprimida, principalmente da classe média. Nas demais indústrias, estavam empregados 3,8\% dos trabalhadores. Esse ainda é um segmento incipiente, e é um desafio para os futuros governos a busca por novas alternativas industriais para o DF. Os demais 9,3\% estavam empregados em outros ramos de atividade, como a agropecuária.

O mesmo estudo aponta uma redução no nível de desemprego do DF, no período entre 2000 e início de 2010 , passando de $14 \%$ da população economicamente ativa (PEA) para 9,6\%.

Tabela 2 - Evolução do pessoal ocupado (mil pessoas) no Distrito Federal por atividade econômica, de 1960 a 2010

\begin{tabular}{l|r|r|r|r|r|r}
\hline Atividade econômica & \multicolumn{1}{|c|}{1960} & \multicolumn{1}{|c|}{1970} & 1980 & 1992 & \multicolumn{1}{c}{2000} & \multicolumn{1}{c}{2010} \\
\hline Indústria de transformação & 4 & 9 & 24 & 28 & 27 & 45 \\
Construção civil & 38 & 33 & 46 & 36 & 27 & 68 \\
Comércio & 5 & 7 & 53 & 96 & 98 & 195 \\
Serviços & 15 & 60 & 190 & 266 & 327 & 583 \\
Administração pública & 7 & 53 & 138 & 198 & 202 & 190 \\
Outros & 2 & 6 & 11 & 7 & 5 & 111 \\
Total & 71 & 178 & 462 & 631 & 686 & 1.192 \\
\hline
\end{tabular}

Fonte: elaboração dos autores com base em Codeplan (2010), PED-DF, convênio Setrab-GDF, Seade-SP e Departamento Intersindical de Estatística e Estudos Socioeconômicos (DIEESE, 2010).

Ressalte-se que, no caso da construção civil, há uma situação peculiar: observa-se que a população menos privilegiada financeiramente está sendo deslocada cada vez mais para novas regiões mais afastadas dentro do DF e, em alguns casos, para a região do entorno, que comporta 19 cidades goianas e três cidades mineiras. Muitas pessoas que moram em cidades dessa região, trabalham e utilizam serviços públicos do DF, configurando uma interdependência reconhecida pelos seus governos. 
Mas, nem sempre foi assim. No início, mais de $60 \%$ da atividade econômica estava voltada para a indústria da construção civil. Quando a cidade passou a ter condições, houve a transferência das instituições públicas do Rio de Janeiro, antiga capital federal, para Brasília, e, consequentemente, dos servidores públicos. Para irem morar na nova capital, esses funcionários receberam uma série de vantagens, como habitação, ajuda de custo e de transporte para o trabalho, dentre outros benefícios. Dessa forma, de acordo com dados do Dieese (2010), o número de servidores públicos, que em 1960 era de apenas 7 mil, passou para 138 mil em 1980, 202 mil no ano 2000, e hoje conta com cerca de 190 mil. Em termos percentuais, essa participação já representou mais de $30 \%$ da população trabalhadora da capital federal, representando, em 2010, $16 \%$.

Esse novo mercado consumidor atraiu o interesse de empresários do comércio, o que elevou o número de empregados do setor de 5 mil trabalhadores, em 1960, para 53 mil em 1980, 98 mil no ano 2000 e 195 mil em 2010. Percentualmente, a participação do comércio passou de 7\%, à época da inauguração da capital, para cerca a de 15\% na década de 1990. Em 2010 o comércio absorveu 16,5\% do total de trabalhadores de Brasília.

Devido à sua característica de cidade administrativa, o servidor público ainda é o principal consumidor do Distrito Federal. Dados do Dieese, porém, demonstram que o setor de serviços, exclusive o serviço público, apresentava-se, em 2010, como o principal empregador de Brasília, totalizando 583 mil empregados, englobando quase $50 \%$ dos empregos existentes.

Outro dado importante é sobre a evolução salarial da população do DF. Informe da Secretaria de Estado de Planejamento do Distrito Federal (Seplan-DF) destaca que, não diferente da situação do resto do país, o mercado salarial de Brasília, até o início de 2003, sofreu com arrochos que visavam ao controle de preços. A partir de então, no entanto, houve uma melhoria substancial, em função dos rendimentos terem aumentado em ritmo superior ao crescimento populacional. Assim, a taxa de crescimento do PIB do Brasil, entre 2003 e 2008, foi de 4,7\% ao ano, enquanto que a população cresceu à taxa de $1,2 \%$ ao ano. Segundo informações da Seplan-DF (2013), o Distrito Federal acompanhou o desempenho do país. Apesar do desempenho dos setores industrial e agrícola não atingirem o mesmo desempenho, em virtude de sua pequena representatividade na economia do DF, esse fator foi compensado pelo desempenho da administração pública no período. Dessa forma, o PIB do DF per capita, nos valores referentes a 2006 , foi de $\mathrm{R} \$ 37,6$ mil, o maior do país. Porém, o crescimento da renda per capita do brasileiro (4,5\% em 2007 e 4,0\% em 2008) foi superior ao do apresentado no DF no mesmo período (3,3\% e 2,5\%, 
respectivamente). Esse fato pode ser explicado pelo crescimento populacional do DF ter sido de 2,5\% ao ano, superior ao nacional, que foi de $1,2 \%$ ao ano.

Esse crescimento populacional ocorreu em proporções ainda maiores na periferia metropolitana de Brasília. Segundo dados do censo demográfico IBGE (2010), enquanto a população do DF apresentou um crescimento de cerca de $60 \%$ nos últimos 20 anos (1,6 milhão de habitantes em 1991 para 2,05 milhões em 2000, e 2,57 milhões em 2010), a região periférica, constante do entorno, apresentou uma evolução populacional de $140 \%$ no mesmo período (380 mil habitantes em 1991, 702 mil em 2000, e 914 mil em 2010). Essa evolução ajuda a explicar os 111 mil trabalhadores alocados no grupo "Outros" da Tabela 2. Esse grupo inclui em sua composição os trabalhadores domésticos com carteira assinada ou diaristas bem como outras atividades oriundas da economia informal. Devido à baixa remuneração, boa parte desses trabalhadores do DF reside na região do entorno, onde o custo habitacional é inferior.

No que se refere ao saldo de empregos com carteira assinada, ou seja, pelo regime celetista, pode-se observar, de acordo com a Tabela 3, que percentualmente, com exceção do Mato Grosso do Sul, todos os estados da Região Centro-Oeste do Brasil, no período de 2007 a 2010, evoluíram com taxas acima de $20 \%$.

Tabela 3 - Saldo da evolução do nível de emprego com carteira assinada nos estados da Região Centro-Oeste, 2007 - 2010

\begin{tabular}{l|c|c|c|c}
\hline \multicolumn{1}{c|}{ Setores } & $\begin{array}{c}2007 \\
(\mathrm{a})\end{array}$ & $\begin{array}{c}2010 \\
(\mathrm{~b})\end{array}$ & $\begin{array}{c}\text { Variação absoluta } \\
(\mathrm{c}=\mathrm{b}-\mathrm{a})\end{array}$ & $\begin{array}{c}\text { Variação percentual } \\
(\mathrm{c}=\mathrm{b} / \mathrm{a})^{\star} 100-100\end{array}$ \\
\hline Região Centro-Oeste & 262.222 & 319.304 & 57.082 & $21,8 \%$ \\
Mato Grosso do Sul & 51.058 & 58.915 & 7.857 & $15,4 \%$ \\
Mato Grosso & 56.111 & 70.788 & 14.677 & $26,3 \%$ \\
Goiás & 107.391 & 130.518 & 23.127 & $21,5 \%$ \\
Distrito Federal & 47.662 & 58.994 & 11.332 & $23,8 \%$ \\
\hline
\end{tabular}

Fonte: elaboração dos autores com base em dados do MTE - Caged, 2013.

\section{Metodologia}

O método shift-share permite fazer uma análise comparativa dos setores que compõem o modelo. Analisou-se a composição do emprego, segundo os três setores da economia, nos estados que compõem a Região Centro-Oeste e na própria área do DF. Esse método propõe analisar um determinado componente de variação por meio da decomposição de uma "dada variável, medida a nível regional, em fatores distintos que possam influenciar o seu comportamento” (SILVA, 2005, p. 797). 
Segundo Haddad e Andrade, "este método descreve o crescimento regional em termos de sua estrutura produtiva e setorial, sendo inteiramente baseado em relações contábeis e definições" (1989, p. 259). Para tanto, utilizar essa metodologia como forma de verificação da estrutural-diferencial dos setores econômicos fornece ao pesquisador informações que podem auxiliá-lo na análise dos fatores locacionais.

Souza (2002) define o termo estrutural como algo referenciado ao setor analisado sob a perspectiva do dinamismo "no contexto da economia nacional comparado a outros setores". Se for negativo, pode-se considerar o setor como estagnado, no caso de ser positivo, como um setor dinâmico na economia para a variável estudada (número de pessoas ocupadas).

O termo diferencial tem seu embasamento nos fatores locacionais. Quando ele é positivo tem-se um movimento de especialização em favor da região, como uma presença maior de setores que empregam mais pessoas. Se o termo diferencial for negativo, a região está perdendo competitividade naquele setor frente ao restante da economia nacional (Região Centro-Oeste, no caso) (SOUZA, 2002).

A definição da estrutural e do diferencial são requisitos básicos para a análise do crescimento dos setores na região. Assim, pode-se compreender sua fórmula, de acordo com Silva (2005, p. 798), por meio da equação (1).

$$
\sum_{K} \Delta X_{i k}=\sum_{K}\left[X_{i k}(t)-X_{i k}(t-1)\right]=\sum_{K}\left[N X_{i k}+S X_{i k}+R X_{i k}\right]
$$

Em que:

$\Delta X_{i k}$ representa a variação observada na variável $X_{i k}$;

$X_{i k}(t)$ representa a variação econômica $X$ (usualmente o emprego ou produto) medida na região $i$, no setor $k$, e no momento $t$;

$N X_{i k}$ representa a componente nacional;

$S X_{i k}$ representa a componente setorial ou estrutural;

$R X_{i k}$ representa a componente regional, concorrencial ou diferencial.

Por meio desse modelo é analisada a:

[...] evolução de uma dada variável econômica como função de três fatores principais: o efeito do crescimento nacional (componente nacional), o efeito da composição setorial da região (componente estrutural) e, ainda, o efeito de outros fatores específicos da região (componente regional, concorrencial ou diferencial) (SILVA, 2005, p.798).

Tais componentes analisados pelo autor (nacional, estrutural e regional, concorrencial ou diferencial) podem ser analisados pelo conjunto de equações (2). 


$$
\begin{aligned}
& N X_{i k}=g_{N X} x X_{i k}(t-1) \\
& S X_{i k}=\left(g_{N X k}-g_{N X}\right) x X_{i k}(t-1) \\
& R X_{i k}=\left(g_{i k}-g_{N X k}\right) x X_{i k}(t-1)
\end{aligned}
$$

No qual:

$g_{N X}$ é a variação percentual da variação $X$ observada a nível nacional (Região Centro-Oeste), relativamente ao ano base $t-1$;

$g_{N X k}$ é a variação percentual da variável $X$ observada a nível nacional (Região Centro-Oeste), referente ao setor $k$;

$g_{i k}$ é a variação percentual da variável $X$, observada na região (unidade da federação) $i$, no setor $k$.

O método shift-share (diferencial-estrutural) possui como característica predominante uma "variação formal comumente utilizada para trabalhos focalizados na identificação de fontes de crescimento, desempenho e indicadores, [...] estimam-se efeitos área, rendimento, localização, produtividade, etc.” (SIMÕES, 2005, p. 12).

Stilwell (1969) sugeriu uma modificação para captar diversificações setoriais entre períodos, criando uma variação revertida (T). A diferença entre a variação revertida e a variação estrutural (E) é denominada variação estrutural modificada (M). Retirando-se $\mathrm{M}$ da variação diferencial (D), obtém-se a variação residual diferencial (RD), compondo-se as três variações ( $\mathrm{E}, \mathrm{M}, \mathrm{RD})$, que proporcionam sua tipologia de 14 variações - em vez das seis originais do método. As variações $\mathrm{E}$ e RD têm a mesma interpretação, mas o interessante dessa redefinição de Stilwell é que a variação $M-$ por ser ponderada não pelo ano-base $t=0$, mas por $t=1$ - pode indicar algum sentido dinâmico prospectivo, mostrando vantagens ou desvantagens setoriais/regionais.

Outro desdobramento merecedor de atenção é o de Esteban-Marquillas (1972), que introduz os efeitos competitivo (D) e alocação (A) aos efeitos estrutural e diferencial. O efeito alocação nos mostra se a região j está especializada nos setores para os quais dispõe de melhores vantagens competitivas ou não. Existem ainda trabalhos, como o de Brown (1969), que utilizam o método diferencial-estrutural para projeção intertemporal da variável-base.

Foi considerado como componente estrutural os setores primário, secundário e terciário da economia. Já seu componente regional foi analisado levando em consideração as unidades da federação Mato Grosso do Sul, Mato Grosso, Goiás e Distrito Federal. O conjunto das unidades da federação (Região Centro-Oeste) foi tratado como componente "nacional". 


\section{Análises e conclusões}

O Cadastro Geral de Emprego e Desemprego (Caged), do Ministério do Trabalho, apresenta os dados da composição empregatícia celetista, conforme ilustra a Tabela 4.

Tabela 4 - Número de pessoas ocupadas por unidade da federação da Região Centro-Oeste (CO) e setor da economia em 2007 e 2010

\begin{tabular}{l|r|r|r|r|r|r|r|r|r|r}
\hline \multirow{2}{*}{ Setor } & \multicolumn{2}{|c|}{ MS } & \multicolumn{2}{c|}{ MT } & \multicolumn{2}{c|}{ GO } & \multicolumn{2}{c}{ DF } & \multicolumn{2}{c}{ CO } \\
\cline { 2 - 11 } & \multicolumn{1}{|c|}{2010} & 2007 & \multicolumn{1}{c|}{2010} & 2007 & \multicolumn{1}{c|}{2010} & \multicolumn{1}{c|}{2007} & 2010 & 2007 & 2010 & 2007 \\
\hline Primário & 19.117 & 18.251 & 17.653 & 14.497 & 28.286 & 25.485 & 1.331 & 1.201 & 66.387 & 59.434 \\
Secundário & 5.375 & 4.094 & 8.907 & 6.564 & 17.889 & 13.657 & 6.569 & 4.512 & 38.740 & 28.827 \\
Terciário & 34.42 & 28.713 & 44.317 & 35.050 & 84.343 & 68.249 & 51.094 & 41.949 & 214.177 & 173.961 \\
Total & 58.915 & 51.058 & 70.877 & 56.111 & 130.518 & 107.391 & 58.994 & 47.662 & 319.304 & 262.222 \\
\hline
\end{tabular}

Fonte: elaboração dos autores com base em dados do MTE - Caged, 2013.

De acordo com os dados da Tabela 5, pode-se afirmar que o estado de Mato Grosso e o Distrito Federal tiveram desempenhos superiores ao total da região e que o desempenho de Goiás é praticamente igual ao da Região Centro-Oeste como um todo. Ao se analisar os dados por setor, detecta-se que uma vantagem do Distrito Federal no setor secundário, em que houve, em termos percentuais, um saldo altamente positivo na indústria da construção civil, com 1.703 empregos, representando $83 \%$ do resultado alcançado nesse setor como um todo. Já no caso de Mato Grosso, observa-se um desempenho superior no setor primário, com predominância absoluta da agricultura.

Tabela 5 - Variação absoluta e relativa do número de pessoas ocupadas por unidade da federação da Região Centro-Oeste e setor da economia, 2007 a 2010

\begin{tabular}{l|r|r|r|r|r|r|r|r|r|r}
\hline \multirow{2}{*}{ Setor } & \multicolumn{2}{|c|}{ MS } & \multicolumn{2}{c|}{ MT } & \multicolumn{2}{c|}{ GO } & \multicolumn{2}{c|}{ DF } & \multicolumn{2}{c}{ CO } \\
\cline { 2 - 10 } & Absoluta & Relativa & Absoluta & Relativa & Absoluta & Relativa & Absoluta & Relativa & Absoluta & Relativa \\
\hline Primário & 866 & $4,7 \%$ & 3.156 & $21,8 \%$ & 2.801 & $11,0 \%$ & 130 & $10,8 \%$ & 6.953 & $11,7 \%$ \\
Secundário & 1.281 & $31,3 \%$ & 2.343 & $35,7 \%$ & 4.232 & $31,0 \%$ & 2.057 & $45,6 \%$ & 9.913 & $34,4 \%$ \\
Terciário & 5.710 & $19,9 \%$ & 9.267 & $26,4 \%$ & 16.094 & $23,6 \%$ & 9.145 & $21,8 \%$ & 40.216 & $23,1 \%$ \\
Total & 7.857 & $15,4 \%$ & 14.766 & $26,3 \%$ & 23.127 & $21,5 \%$ & 11.332 & $23,8 \%$ & 57.082 & $21,8 \%$ \\
\hline
\end{tabular}

Fonte: elaboração dos autores com base em dados da pesquisa. 
No que se refere ao componente estrutural (Tabela 6), dado pela participação relativa de cada setor da economia em relação à participação relativa total, pode-se observar uma perda de participação do setor primário em relação aos demais. $\mathrm{O}$ setor secundário é o que tem maior crescimento relativo, boa parte devido ao atual momento vivenciado pela atividade de construção civil.

Tabela 6 - Cálculo do componente estrutural

\begin{tabular}{l|r|r|r|r|r|r|r|r}
\hline \multirow{2}{*}{ Setor } & \multicolumn{2}{|c|}{ MS } & \multicolumn{2}{c|}{ MT } & \multicolumn{2}{c|}{ GO } & \multicolumn{2}{c}{ DF } \\
\cline { 2 - 9 } & Var. rel. & Comp. Est. & Var. rel. & Comp. Est. & Var. rel. & Comp. Est. & Var. rel. & Comp. Est. \\
\hline Primário & $-10,1 \%$ & -1.838 & $-10,1 \%$ & -1.460 & $-10,1 \%$ & -2.566 & $-10,1 \%$ & -121 \\
Secundário & $12,6 \%$ & 517 & $12,6 \%$ & 828 & $12,6 \%$ & 1.723 & $12,6 \%$ & 569 \\
Terciário & $1,3 \%$ & 387 & $1,3 \%$ & 473 & $1,3 \%$ & 921 & $1,3 \%$ & 566 \\
Total & $-1,8 \%$ & -934 & $-0,3 \%$ & -159 & $0,1 \%$ & 78 & $2,1 \%$ & 1.014 \\
\hline
\end{tabular}

Fonte: elaboração dos autores com base em dados da pesquisa.

Com relação ao componente regional (Tabela 7), existe uma relação favorável ao Mato Grosso, principalmente no que concerne ao setor primário, e ao Distrito Federal, especialmente quando se analisa o setor secundário.

Tabela 7 - Cálculo do componente regional

\begin{tabular}{l|r|r|r|r|r|r|r|r}
\hline \multirow{2}{*}{ Setor } & \multicolumn{2}{|c|}{ MS } & \multicolumn{2}{|c|}{ MT } & \multicolumn{2}{c}{ GO } & \multicolumn{2}{c}{ DF } \\
\cline { 2 - 8 } & $\begin{array}{l}\text { \% est.- } \\
\% \text { reg. }\end{array}$ & Comp. Reg. & $\begin{array}{l}\% \text { est.- } \\
\% \text { reg. }\end{array}$ & Comp. Reg. & $\begin{array}{l}\text { \% est.- } \\
\% \text { reg. }\end{array}$ & Comp. Reg. & $\begin{array}{l}\% \text { est.- } \\
\% \text { reg. }\end{array}$ & $\begin{array}{l}\text { Comp. Reg. } \\
\text { Primário }\end{array}$ \\
\hline Secundário & $-7,0 \%$ & -1.269 & $10,1 \%$ & 1.460 & $-0,7 \%$ & -180 & $-0,9 \%$ & -11 \\
Terciário & $-3,1 \%$ & -127 & $1,3 \%$ & 86 & $-3,4 \%$ & -464 & $11,2 \%$ & 505 \\
Total & $-14,3 \%$ & -2.324 & $12,1 \%$ & 2.710 & $1,1 \%$ & $-1,3 \%$ & -553 \\
\hline
\end{tabular}

Fonte: elaboração dos autores com base em dados da pesquisa.

Dessa forma, ao se analisar a evolução do emprego celetista na Região Centro-Oeste do Brasil, tem-se um crescimento de 57.052 empregos no período, conforme ilustra a Tabela 8. 
Tabela 8 - Composição do crescimento em componentes de variação

\begin{tabular}{l|r|r|r|r|r|r|r|r}
\hline \multirow{2}{*}{ Região } & \multicolumn{2}{|c|}{$\begin{array}{c}\text { Componente estrutural } \\
(1)\end{array}$} & \multicolumn{2}{|c|}{$\begin{array}{c}\text { Componente estadual } \\
(2)\end{array}$} & $\begin{array}{r}\text { Componente regional } \\
(3)\end{array}$ & \multicolumn{2}{|c}{$\begin{array}{c}\text { Variação efetiva } \\
(1)+(2)+(3)\end{array}$} \\
\cline { 2 - 9 } & Relativo & Absoluto & \multicolumn{1}{|c|}{ Relativo } & Absoluto & Relativo & Absoluto & Relativo & Absoluto \\
\hline MS & $-1,8 \%$ & -934 & $-14,3 \%$ & -2.324 & $21,8 \%$ & 11.115 & $15,4 \%$ & 7.857 \\
MT & $-0,3 \%$ & -159 & $12,1 \%$ & 2.710 & $21,8 \%$ & 12.215 & $26,3 \%$ & 14.766 \\
GO & $0,1 \%$ & 78 & $1,1 \%$ & -328 & $21,8 \%$ & 23.377 & $21,5 \%$ & 23.127 \\
DF & $2,1 \%$ & 1.014 & $1,1 \%$ & -58 & $21,8 \%$ & 10.375 & $23,8 \%$ & 11.332 \\
\hline
\end{tabular}

Fonte: elaboração dos autores com base em dados da pesquisa.

Desse total, Goiás é o estado que mais participa em termos absolutos, embora, relativamente, a maior participação esteja configurada no Mato Grosso. O Distrito Federal apresentou componente estrutural altamente favorável, principalmente nos setores secundário e terciário.

Pode-se concluir, portanto, que o componente regional teve uma contribuição positiva sobre o emprego formal em todos os setores no estado do Mato Grosso. Já o componente estrutural foi positivo no Distrito Federal e em Goiás, considerando os setores secundário e terciário. Nesses estados, o componente estrutural foi negativo no setor primário. Em Mato Grosso do Sul, o componente estrutural também foi positivo nos setores secundário e terciário, no entanto, negativo no setor primário. Apenas no Mato Grosso, o setor primário teve um desempenho favorável no componente regional. 


\title{
The importance of the Federal District in the composition of the private law based labor market the Midwest Region of Brazil
}

\begin{abstract}
This study aims to demonstrate the socioeconomic importance of the Federal District for the Midwest region, considering the historical and geographical context, noting their characteristics and demographic trends and labor market. The methodological approach was based on secondary data and using the shift-share model. The results show that the regional component had a positive contribution to formal employment in all sectors in the state of Mato Grosso. The structural component was positive in the Federal District and Goiás, considering the secondary and tertiary sectors. In these states, the structural component was negative in the primary sector. In Mato Grosso do Sul structural component was also positive in secondary and tertiary sectors, but was negative in the primary sector. Only in Mato Grosso, the primary sector had a positive performance in the regional component.
\end{abstract}

Keywords: Federal District. Midwest. Socio-Economic. Composition of jobs. Shift-share.

\section{La importancia del Distrito Federal en la composición del mercado laboral bajo leyes privadas en la Región Centro-Oeste de Brasil}

\section{Resumen}

El estudio demuestra la importancia socioeconómica del Distrito Federal para la región del Centro-Oeste, teniendo en cuenta el contexto histórico y geográfico, tomando nota de sus características y las tendencias demográficas y del mercado laboral. El enfoque metodológico se basó en datos secundarios y utilizando el modelo shift-share. Los resultados muestran que el componente regional tuvo una contribución positiva en el empleo formal en todas las industrias en el estado de Mato Grosso. Dado que el componente estructural fue positiva en el Distrito Federal y Goiás, teniendo en cuenta los sectores secundario y terciario. En estos estados, el componente estructural fue negativo en el sector primario. En Mato Grosso do Sul componente estructural también fue positiva en los sectores secundario y terciario, pero fue negativo en el sector primario. Sólo en Mato Grosso del sector primario tuvo un desempeño positivo en el componente regional.

Palabras clave: Distrito Federal. Centro-Oeste. Socioeconómico. Composición de empleos. Shift-share. 


\section{Referências}

BERTRAN, P. Uma introdução à história econômica do Centro-Oeste do Brasil. Brasília: Universidade Católica de Goiás; Companhia de Planejamento do Distrito Federal, 1998.

BROWN, H. J. Shift and share projection of regional economic growth: an empirical test. Journal of Regional Science, Malden, v. 9, n. 1, p. 1-8, 1969.

CODEPLAN. COMPANHIA DE PLANEJAMENTO DO DISTRITO FEDERAL. Publicações técnicas. Brasília: Codeplan, 2010.

DIEESE. DEPARTAMENTO INTERSINDICAL DE ESTATÍSTICA E ESTUDOS SOCIOECONÔMICOS. Indicadores do mercado de trabalho. São Paulo: Dieese, 2010.

ESTEBAN-MARQUILLAS, J. M. A reinterpretation of shift-share analysis. Regional and Urban Economics, Amsterdam, v. 2, n. 3, p. 249-255, 1972.

HADDAD, P. R.; ANDRADE, T. A. Método de análise diferencial-estrutural. In: HADDAD, P. R. (Org.). Economia regional: teorias e métodos de análise. Fortaleza: BNB, 1989. p. 249-286.

IBGE. INSTITUTO BRASILEIRO DE GEOGRAFIA E ESTATÍSTICA. Contas regionais do Brasil. Rio de Janeiro: IBGE, 2009. set. 2014 .

Censo demográfico. 2010. Disponível em: <http://www.sidra.ibge.gov.br>. Acesso em: 25

MINISTÉRIO DA INTEGRAÇÃO NACIONAL. Plano estratégico de desenvolvimento do Centro-Oeste (2007-2020). Brasília: MIN, 2014.

MIRAGAYA, J. Industrialização: questão vital para o futuro da capital. Revista de Conjuntura, Brasília, n. 41, p. 3-9, jan./mar. 2010.

MTE. MINISTERIO DO TRABALHO E EMPREGO. Cadastro Geral de Empregados e Desempregados. Disponível em: <http://portal.mte.gov.br/caged/>. Acesso em: 30 ago. 2014.

PAGNUSSAT, J. L. Brasília: 50 anos de desenvolvimento. Revista de Conjuntura, Brasília, n. 41, p. 22-25, jan./mar. 2010.

SILVA, J. C. C. da. A análise de componentes de variação (shift-share). In: COSTA, J. S. Compêndio de economia regional. Coimbra: Associação Portuguesa para o Desenvolvimento Regional, 2005. p. 797-807.

SIMÕES, R. F. Métodos de análise regional e urbana: diagnóstico aplicado ao planejamento. Belo Horizonte: UFMG/Cedeplar, 2005.

SOUZA, C. C. A. de. Área Metropolitana de Belo Horizonte versus Área Metropolitana de Curitiba: um estudo comparativo dos fatores de atração. Dissertação (Mestrado em Economia) - Universidade Federal de Minas Gerais, Minas Gerais, 2012.

STILWELL, F. Regional growth and structural adaptation. Urban Studies, Stanford, v. 6, p. 162178, 1969.

TIMM, P. Brasília, 50 anos - parte 1. Revista de Conjuntura, Brasília, n. 41, p. 35-43, jan./mar. 2010. 